\title{
Developmental biology of the tiger moth, Atteva sciodoxa Meyrick (Lepidoptera: Yponomeutidae) under laboratory conditions
}

\begin{abstract}
The tiger moth, Atteva sciodoxa is a serious pest of tongkat Ali, Eurycoma longifolia. The morphology, development times and fecundity aspects were studied at $27 \pm 2{ }^{\circ} \mathrm{C}, 90 \pm 5 \%$ relative humidity and $12 \mathrm{~h}$ photoperiod. The eggs were yellow and ovoid in shape with a mean length and width of $1.19 \pm 0.02$ and $0.86 \pm 0.02 \mathrm{~mm}$, respectively. Width measurements of larval head capsules showed that A. sciodoxa undergoes five larval instar stages. The mean head capsule widths of the first to fifth instar larvae were $0.55 \pm 0.01,0.89 \pm 0.01,1.23 \pm 0.02$, $1.52 \pm 0.01$ and $2.11 \pm 0.02 \mathrm{~mm}$, while the body lengths were $4.71 \pm 0.1,8.63 \pm 0.1,12.87 \pm 0.1$, $16.29 \pm 0.1$ and $21.74 \pm 0.2 \mathrm{~mm}$, respectively. The mean male and female pupal body lengths were $10.36 \pm 0.1$ and $11.26 \pm 0.2 \mathrm{~mm}$, respectively. The mean male and female wing span were $21.63 \pm 0.2$ and $24.28 \pm 0.2 \mathrm{~mm}$, respectively. The mean pre-oviposition and oviposition periods were $6.2 \pm 0.23$ and $8.5 \pm 0.28$ days, respectively. A single female laid on average 106.1 \pm 4.85 eggs with maximum production between days 8-15 of adult emergence. The maximum number of eggs laid per female per day was $20.1 \pm 0.5$. The mean hatching time was $5.7 \pm 0.1$ days with a mean hatchability of $81.1 \pm 0.6 \%$. The mean larval, pupal and adult periods were $20.7 \pm 0.2,6.2 \pm 0.8$ and $13.2 \pm 0.5$ days, respectively. The female pupal period and adult lifespan were significantly longer than the male. Atteva sciodoxa completed its life cycle in $46.28 \pm 0.49$ days.
\end{abstract}

Keyword: Atteva sciodoxa, Development, Eurycoma longifalia, Tongkat Ali 